\title{
Injurias, maldiciones y juramentos en la lengua española del siglo XVII
}

CRISTINA TABERNERO SALA

GRISO-Universidad de Navarra

\section{INTRODUCCIÓN}

Las palabras como instrumento de agresión verbal a Dios o a los hombres han constituido delito punible desde los primeros textos jurídicos del español, circunstancia que ha provocado su análisis desde perspectivas de estudio diferentes - lingüística, literaria, histórica o jurídica-, dirigidas todas ellas al mayor entendimiento de un mismo hecho. El panorama que arrojan los siglos XVI y XVII resulta a este respecto especialmente representativo pues, como han llegado a afirmar algunos historiadores, Europa avanzaba en aquel momento hacia una «civilización de la blasfemia» ${ }^{1}$. Fórmulas blasfematorias y juramentos, palabras vedadas o malas palabras que injurian han formado parte de los usos sancionados por la legislación medieval y han entrado en los textos literarios en la medida en que estos se han hecho eco de la variación lingüística constatable en la lengua de aquellas épocas. El reflejo de un léxico más propio de la oralidad que de la escritura, sociolingüísticamente marcado, con registro lexicográfico en ocasiones, aumentó considerablemente en la literatura áurea, en la pluma de autores que plasmaron un retrato social de luces y de sombras.

De acuerdo con las funciones del lenguaje establecidas por R. Jakobson, las imprecaciones, insultos o palabras malsonantes pueden emplearse ( $c f$. Castillo 2004: 24-25) con valor referencial, uso que en términos jurídicos implicaría delito de difamación; se usan también con predominio de la función conativa, «cuando el hablante profiere el insulto directamente contra su interlocutor causando una reacción en él» (Castillo 2004: 24-25), es decir, cometiendo delito de injurias, y con función expresiva, «cuando se profieren no solo insultos, sino también obscenidades, maldiciones y blasfemias

\footnotetext{
* Este artículo se enmarca en el Proyecto de Investigación Fundamental «Edición crítica del teatro completo de Tirso de Molina. Tercera fase» (FFI2010-18619/FILO), subvencionado por el Ministerio de Ciencia e Innovación de España.

${ }^{1}$ Expresión acuñada por intelectuales coetáneos de aquella época y por historiadores actuales, si bien no han faltado voces que la han calificado de exagerada e imprecisa. $C f$. para estos datos Usunáriz (2005: 197 y n. 4).
} 
desviados de su función propia y original» (Castillo 2004: 25), sin valor referencial ni conativo, solo interjectivo.

$\mathrm{Su}$ formulación ha ido variando de acuerdo con los diferentes momentos de lengua como reflejo de una cultura y de una sociedad también cambiantes ${ }^{2}$. De hecho, algunos autores han mencionado la inestabilidad como característica de las malas palabras ( $c f$. Casas 1986) y, por ende, la naturaleza sincrónica de aquellas en la medida en que son producto de un momento y de un grupo determinados ( $c f$. Colín 2003: 38), cuyo uso está marcado sociolingüísticamente como caracterizador del habla de individuos de nivel popular y de estilo generalmente denominado coloquial o informal, que, salvo imitación intencionada, generalmente literaria, se vincula con mayor frecuencia a las producciones orales que a las escritas. Por tanto, no ha de ser despreciable como contribución al diseño de una parte de la historia del español el análisis del léxico empleado en el siglo XVII en la formulación de injurias, maldiciones y blasfemias a través del análisis de relaciones de causas de fe despachadas por el Tribunal de la Inquisición de Logroño en la centuria mencionada.

Las páginas que siguen se basan, pues, en la revisión de unas seiscientas veinte relaciones, fechadas entre el 20 de julio de 1620 y el 20 de julio de 1655 y conservadas en el Archivo Histórico Nacional (sección Inquisición), a las que he tenido acceso gracias a la amabilidad y generosidad del especialista en Historia Moderna J. M. Usunáriz. El trabajo se ha realizado sobre la documentación original, por lo que he actualizado únicamente la puntuación y la acentuación, la separación de palabras y las mayúsculas. Con este criterio se han intentado evitar en el lector errores o dudas de interpretación que podrían suscitarse debido al carácter fragmentario de los testimonios recogidos.

Es de sobra conocido que otros trabajos antes que el mío han empleado como fuente de estudio documentación inquisitorial ( $c f$. Eberenz 1994, 1998, 2003 y Eberenz y De la Torre 2003), sobre todo como textos que puedan proporcionar datos acerca de la oralidad de épocas del español de las que, evidentemente, se posee mayoritariamente documentación escrita de registro formal, ya sea jurídico o literario. No es, por tanto, la originalidad de sus textos lo que pretenden estas líneas sino el estudio de uno de los aspectos predominante en ellas, la verbalización de la agresividad con la que durante siglos se traspasaban las fronteras de la legalidad. Son las declaraciones orales de reos $\mathrm{y}$ testigos en los procesos inquisitoriales las que dejan hacer acopio de un buen número de manifestaciones de la índole mencionada, provocadas en la mayoría de las ocasiones por el delito mismo - se delinquía con la palabra-, aunque no faltan los testimonios generados por la necesidad del reo de convencer al tribunal de su inocencia.

${ }^{2}$ Se hace necesario recordar aquí los estudios sobre historia social del lenguaje de P. Burke (1996). El lenguaje, según este autor, es un instrumento capaz de impulsar o impedir el cambio social. Como declaró este autor en una entrevista publicada en la red (http://clio.rediris.es/entrevistas/peter_burke.htm), su pretensión, de clara inspiración socio o etnolingüística, era tender un puente entre lingüistas e historiadores. La historia de la lengua ha demostrado también que muchos cambios lingüísticos, especialmente semánticos, se han debido al cambio social. Se trata, por tanto, de un proceso bidireccional. 
No voy a repetir aquí los motivos que justifican la idoneidad de este tipo de escritos para la caracterización de la oralidad de épocas pasadas pues sobre todo R. Eberenz (1994, 1998, 2003), y también J. J. de Bustos Tovar (2004), lo han apuntado ya en diferentes artículos. Valga recordar simplemente el especial interés que debía de tener el escribano en la reproducción fiel de los testimonios de testigos y encausados en cuanto justificación de la sentencia final, tanto más cuanto que en muchas ocasiones, como se apuntaba más arriba, el presunto delito es propiamente la palabra o el acto de la enunciación, si se atiende a las indicaciones de tipo pragmático que constan en los textos («auia dicho con mucha colera que renegaua de dios y de su madre», AHN, 1621 , lib. $\left.836, \mathrm{f}^{2} 273 v\right)^{3}$ y que constituyen circunstancias atenuantes o agravantes del cargo imputado.

El corpus de este trabajo difiere del manejado por otros autores en la medida en que no se trata de las causas inquisitoriales propiamente dichas sino de sus relaciones, que permiten algunas ventajas sobre los procesos completos: el relator ha de dejar constancia de lo pronunciado exactamente por el reo y por los testigos; por tanto, aunque las elocuciones sean más breves que en la constatación íntegra, el léxico ${ }^{4}$, aspecto analizado en este trabajo, se recoge por ser propiamente la causa del delito. De otro lado, la misma brevedad de los relatos vuelve factible la revisión de un mayor número de ellos $\mathrm{y}$, en consecuencia, el acercamiento a un período cronológico más amplio, si bien por el momento se han acotado - por razones de espacio- las fronteras temporales.

Los testimonios que aparecerán citados más adelante pertenecen, como ya se ha mencionado, a documentación fechada entre 1620 y 1655 en los que he intentado recopilar los términos y expresiones empleados por los hablantes del siglo XVII en situaciones diversas como las de embriaguez, cólera o similares, y ligados habitualmente, como se comprobará, a individuos del pueblo, lo que ha de servir para la ubicación sociolingüística del discurso constatado en estos papeles. Estos textos agrupan todo tipo de delitos por imprecación que fueron objeto de encausamiento por parte del Santo Oficio.

${ }^{3}$ Bustos (2004: 62) reconoce el valor de las actas inquisitoriales para el estudio de la oralidad en la escritura, especialmente para el estudio de la sintaxis discursiva y no tanto para el conocimiento del léxico coloquial debido a lo limitado de su universo nocional. Estas palabras, que cobran todo su sentido cuando se trata de causas de herejía o de brujería, podrían matizarse tal vez en los delitos por injurias y blasfemias, donde el término injurioso o blasfematorio objeto de causa inquisitorial suele ir acompañado de otro tipo de léxico no restringido al ámbito religioso. Particularmente interesante parece mostrarse esta documentación para obtener algunos datos sobre el cambio de nivel de lengua o, quizás, de estilo, que ha podido operarse en algunos términos o expresiones así como para la adscripción al lenguaje familiar de determinados vocablos, o para la constatación de voces no documentadas (encluequecer "ponerse clueca la gallina', veninezca 'se envenene', (muger) andada (mujer) 'promiscua') o escasamente (chiflo 'especie de silbato'). Cf. para las cuestiones de documentación y uso, CORDE: por ejemplo, de chiflo se recogen únicamente 18 casos en 9 documentos y solo tres de ellos pertenecen a fechas anteriores al siglo XVII (dos en el Universal Vocabulario de A. de Palencia y otro en las Cartas a unos amigos de E. de Salazar, de 1573). Como se puede comprobar, chiflo se constata lexicográficamente en contraposición a los testimonios casi inexistentes.

${ }^{4}$ Ha de citarse aquí la contribución de Montero (2007) al estudio del léxico de la oralidad en las Partidas de Alfonso X. 
Atenderé en lo que sigue a los delitos de injurias y blasfemia, que, según se ha señalado, se materializan verbalmente poniendo en funcionamiento el valor puramente referencial del lenguaje junto al conativo y expresivo.

\title{
2. FÓRMULAS DE JURAMENTO O FÓRMULAS BLASFEMATORIAS
}

Aunque los términos juramento y blasfemia suelen emplearse habitualmente como sinónimos en la lengua común, conviene matizar, siquiera en términos muy generales y sin ánimo de centrar el análisis posterior en la teorización sobre este tema, la distinción existente entre ambos conceptos. Tanto el juramento como la blasfemia consisten en el ultraje del nombre de Dios. Recuerda F. Loetz que los teólogos de la Edad Media establecieron las tres especies que constituyen una blasfemia: «dénier à Dieu ce qui lui appartient, attribuer à Dieu ce qui ne lui appartient pas, associer à un autre ce qui appartient à Dieu» (Loetz 1998: 418); tomando esta caracterización teológico-jurídica como base, resulta casi imposible — señala la misma autora - la distinción entre juramento y blasfemia; se puede llegar únicamente a una separación en sentido amplio que entenderá como

jurons et jurements toutes expresssions verbales qui profanent le nom de Dieu, tandis que blasphème dénote une parole par laquelle le locuteur s'approprie ou attribue à quelqu'un d'autre un pouvoir appartenant à Dieu (Loetz 1998: 418).

Asimismo, blasfemia y ruego o petición a Dios están separados por una frontera fácilmente traspasable en la medida en que los segundos pueden convertirse en la primera: «dire vrai sur Dieu (selon l'univers de croyance majoritaire) est prier, dire faux est blasphémer» (Lagorgette 2003: 175).

El juramento, de acuerdo con la idea señalada hace ya mucho tiempo por E. Benveniste, ha de considerarse como la expresión blasfematoria por excelencia ${ }^{5}$, que pertenece al lenguaje. El punto común de los juramentos o locuciones blasfematorias «procède du besoin de violer l'interdiction biblique de prononcer le nom de Dieu. La blasphémie est de bout en bout un procès de parole; elle consiste, dans une certaine manière, à remplacer le nom de Dieu par son outrage» (Benveniste 1974: 255). Añade D. Lagorgette a este respecto:

\begin{abstract}
On peut même dire que la distinction entre juron et blasphème est la même que celle qui oppose apostrophe rhétorique et adresse: l'invocation «réflexe» et le juron, comme la figure de style, sont des apostrophes personnifiées (totalement explétives, ornementales; des formules [...]) tandis que la prière, l'insulte et le blasphème sont des actes opérés para un terme d'adresse axiologique (positif ou négatif selon les cas) (Lagorgette 2003: 177).
\end{abstract}

Resulta lícita, entonces, la indistinción que habitualmente se practica entre juramento y blasfemia, en un contexto al que no afecta la posible imprecisión terminológica que pueda achacarse a la identificación de ambos conceptos. Las fuentes lexicográficas

\footnotetext{
${ }^{5}$ Distingue aquí Benveniste entre esta blasfemia y aquella que supone «assertion diffamante à l'égard de la religion ou de la divinité» (1974: 254).
} 
del español dejan entender igualmente el juramento como blasfemia; desde Autoridades la Academia definió el término juramento como "afirmación, o negación que se hace llamando a Dios por testigo de su verdad, o explícitamente nombrándole, o implícitamente en las criaturas, en quien resplandece su bondad, poder y sabiduría» ( $D A, s$. v.) y blasfemia ( $D A$, s.v. blasphemia) como «lo que impia y sacrilegamente por modo de injúria se dice de Dios, de Maria Santissima, de los Santos, y de las cosas sagradas, aunque el que habla en esta conformidad no dé assenso à las palabras que pronuncia». En adelante, los diccionarios, tanto los académicos como los de Terreros (1787), Núñez (1825), Salvá (1846), Domínguez (1853), Gaspar y Roig (1855), Zerolo (1895), Toro (1901), Pagés (1914), Alemany (1917) o Rodríguez (1918) (cf. NTLLE, s. vv.), mantendrán ambas definiciones con variantes mínimas, más sustanciales en el caso de blasfemia que en el de juramento. En ocasiones se dan, sin embargo, acepciones nuevas que merece la pena mencionar; sucede así con la definición 'juramento que se echa. $\mathrm{V}$. Voto, taco', que aparece en Terreros (s. v.). Es, en cambio, el verbo jurar, y no el sustantivo mencionado - juramento-, el que se penaliza como vicio $(D A, s . v$.) o blasfemia (Gaspar, $s . v$.), a excepción del diccionario de Pagés, de 1914, que ofrece la definición 'voto o reniego' como una de las acepciones de juramento, el mismo autor que añade el uso 'echar votos y reniegos' para el verbo y que continúa la Academia desde su edición de 1914. El juramento y el voto se habían convertido hacía mucho tiempo en un simple instrumento verbal de énfasis, en palabras de E. Ridruejo, vaciándose de cualquier elemento sobrenatural, «de modo que puede figurar un elemento ficticio o incluso el mismo emisor» (2005: 1000, n. 1).

De acuerdo con la crítica planteada ya desde Strawson (1964) a la teoría de los actos de habla, que atribuye la fuerza ilocutiva de aquellos a la intención comunicativa del emisor y no a los componentes semánticos, el juramento, y la blasfemia como ju-

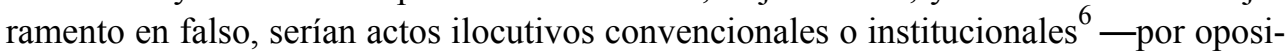
ción a los comunicativos-, que no tendrían existencia fuera de prácticas regidas por convenciones sociales ( $c f$. Ridruejo 2005: 997-998); sin embargo, la fuerza ilocutiva del acto de habla puede quedar restringido al valor meramente comunicativo si se pierde el carácter institucional de aquél, circunstancia que se produce «cuando un acto de este tipo deja de producir su efecto en la realidad porque desaparece la convención social que lo establecía» (Ridruejo 2005: 999). Ocurre de esta manera con el voto, juramento medieval, que, al vaciarse del valor institucional,

queda reducido a un acto comunicativo que ni siquiera tiene carácter comisivo: se emplea para poner por testigo aparente, bien a la divinidad, a una potencia superior, o bien simplemente a la confianza que pueda tenerse en el emisor de la veracidad de una aseveración, lo que en definitiva no consiste sino en un mecanismo de refuerzo de la declaración (Ridruejo 2005: 1000).

\footnotetext{
${ }^{6}$ Esta distinción, como señala el propio Ridruejo, se debe a Warnock (1973) y Bach y Harnisch (1979).
} 
De este modo la blasfemia pasa a ser un acto expresivo cuya fuerza ilocutiva reside en la agresión al receptor, al igual que sucede en el insulto ( $c f$. infra y García-Medall 2008: 667).

En consecuencia, el juramento será blasfemia en la medida en que implique jurar (en falso). Blasfemia y juramento acaban saliendo de la esfera de lo religioso para convertirse, según Autoridades en la segunda acepción de blasfemia, en 'la palabra, ò palabras que injuriosamente se dicen contra alguno, dañándole en la reputación' ( $D A, s$. v.).

Palabras extraídas de la traducción anónima del Libro de las donas de Francesc Eiximenis (1448) dan fe de los usos que constatan las obras lexicográficas:

Capítulo VIII, que muestra que juramento es acto de grant rreuerençia \& cómmo puede omne jurar sin pecado. Juramento non es sinon traer el nonbre de Nuestro Señor Dios en testimonio de verdat. Commo por nuestra miseria no damos fe a las palabras vno de otro, por ende aquel trae a su propósito juramento que sea creýdo $\&$ la contienda que es entre ellos aya fin. E commo traer el nonbre preçioso de Nuestro Señor Dios sea cosa muy alta de sý mesma, por tal el juramento es acto de grant rreuerençia, el qual las gentes deuen contractar con grant temor de Dios \& con grant onor, non jurando vanamente. Por rrazón de aquesto pone el Decreto que aquellos que juran solepnemente deuen jurar en Dios por rreuerençia del sacramento; tales se deuen descobrir las cabeças $\&$ abaxarse fasta tierra $\&$ afinojándose, nin deue asý ninguno jurar sin grant rrazón, \& mayormente persona eclesiástica \& rreligiosa $(C O R D E)$.

En las relaciones de causas inquisitoriales revisadas son numerosísimos los procesos de reos encausados por blasfemia, registrándose, por tanto, un abundante elenco de fórmulas, que constituyen en sí mismas actos constitutivos de delito (voto a Dios ${ }^{7}$, reniego de Dios, reniego de Dios y de sus santos, reniego de Dios y de nuestra señora, reniego de Dios y de la madre que me parió, por vida de Dios, voto a Christo, par Dios), seguidas a veces de enunciados que ofrecen buena muestra del estado anímico en que se encuentra el que las profiere: «dijo: eso sí, voto a Dios, fauor a la justiçia, que son unos desbergonçados» (AHN, 1632, lib. 836, f $580 v$ ), «reniego de dios y de sus santos, que no me lo ha de yr a pagar al otro mundo» (AHN, 1637, lib. 837, fo58r), «votaba a Christo, que a él no se le daba nada del tribunal ni de los Inquisidores», «yo sé la cortesía que he de tener con ellos y, si fuere necesario, meterlos en un puño, voto a Christo» (AHN, 1644, 837, f $242 \mathrm{v}$ ), «voto a Dios que, si esto que digo yo,

${ }^{7}$ Llama la atención que, al transcribir de forma indirecta las palabras que los testigos habían oído pronunciar al reo, se produzca la variación temporal de la expresión «voto a Dios»: «que oyeron deçir al Reo que Votaua a Dios estaua tambien reçiuido en la villa como Dios en el çielo» (AHN, 1636, lib. 837, $\mathrm{f}^{\mathrm{o}} 1 r$ ). Posiblemente pueda interpretarse este cambio como prueba de la estricta fidelidad con la que se reproducen, aunque sea en estilo indirecto, los testimonios de reos y testigos; es lógico que así sea pues en caso de parafrasear la expresión no se transmitiría el delito.

Podrían ratificar la hipótesis anterior estos otros testimonios: «hauía respondido con gran menospreçio, descortesía y desacato, que votaba a Christo que a él no se le daba nada del tribunal ni de los Inquisidores [...] diçiendoles que votaba a Christo que el tribunal del santo offiçio no le hauia de prender por pasiones» (AHN, 1644, lib. 837, 242v). 
no es verdad, que no es verdad lo que está escrito en la missa» (AHN, 1622, lib. 836, fo291r).

Todas estas locuciones se documentan en los textos hispánicos desde la Edad Media con testimonios tanto jurídicos como literarios. Par Dios aparece en dos escritos del siglo XIII —Razón de Amor ( «Par Dios, diz el uino, muchos somos en buena Razon/ si comygo tuuieres entençion» [CORDE]) y Fuero de Ledesma («Todo omne que iurar deue, e coniuramientaren elle, e echaren su periuro, e dixieren: «¿uienes iurar lo que yo te ati demando?» de qual cosa demandar; e el que iura dixier: «par dios si uo e por sancta Maria» [CORDE])—; se recoge esporádicamente en los siglos XIV y $\mathrm{XV}^{8}$ y vuelve en el XIX en los escritos de Bartolomé José Gallardo ( $c f$. CORDE); reniego de Dios (y de sus santos) se constata casi con exclusividad en el Memorial del aucto de Inquisición en Toledo, redactado alrededor de 1579 por Sebastián de Horozco, y en la Historia del Tribunal del Santo Oficio de la Inquisición en Chile (1890), de J. Toribio Medi$\mathrm{na}^{9}$. Las centurias del XVI y del XVII — con predominio de la segunda sobre la primera- son asimismo las que proporcionan noticia del uso de por vida de Dios, principalmente en España, sin olvidar algunos testimonios en las crónicas de Indias:

\section{[...] el mismo Aguirre, le volvió a preguntar: «Pedro Alonso, ¿tenéis tambor?», y respondiéndole que sólo tenía la caja sin parches, le dijo: «Pues ipor vida de Dios que si os arrebato, tengo de hacer de vuestro cuerpo parches para el tambor!» (Fray Pedro Simón, Primera parte de noticias historiales de las conquistas de tierra fir- me en las Indias Occidentales, 1627, CORDE).}

En relación al resto de expresiones mencionadas, aumentan considerablemente las apariciones de por vida de Dios, que son lugar común en la literatura de los siglos de Oro (cf. CORDE).

Voto a Dios y voto a Christo, más común la primera de ellas que la segunda de acuerdo con los testimonios registrados en el CORDE, se circunscriben igualmente a los siglos áureos y cuentan además con presencia lexicográfica desde Covarrubias («Un juramento hay usado entre gente inconsiderada y fanfarrona de «Voto a Dios», sin advertir qué es lo que dicen, ni lo que votan», Tesoro, s. v. voto) y Autoridades («se toma asimismo por juramento, y execracion en demostracion de ira. Llamase assi por empezar regularmente con esta voz la expresión: como Voto a Dios, voto a Christo)». De hecho, la pérdida de institucionalización que se mencionaba más arriba se hace patente en las modificaciones o deformaciones eufemísticas ( $c f$. también supra) a las que antes se hacía referencia, llegando incluso a contar con entrada en diccionarios del XIX y XX como los de Salvá, Domínguez, Gaspar y Roig, Alemany, Rodríguez, que

\footnotetext{
${ }^{8}$ Según los datos recogidos en el CORDE, las apariciones del siglo XIV pertenecen a una misma obra y a tres diferentes las del XV.

${ }^{9}$ El único testimonio que escapa a estas dos obras se registra en Examen de ingenios para las ciencias (1575-1588), del doctor Huarte de San Juan (cf. CORDE).
} 
siguen lo reflejado en las ediciones académicas coetáneas ( $c f$. NTLLE, s. v. votar). Figuran en todos ellos las expresiones votar a bríos, a dios Baco, a tal, a tantos ${ }^{10}$.

Del mismo modo, sirven como referencia de uso y cronología algunas reflexiones metalingüísticas que se encuentran en textos como El Oracional (alrededor de 1456), de Alonso de Cartagena:

E esta manera de fablar ha poco que entró en Castilla, a mi paresçer.

Ca ya veedes muchas vezes dezir quando quieren espremir grand buena voluntad a alguno dizen «fulano mucho es vuestro devoto». E esto creo yo, que aya venido de la vezindad de otras comarcas. Ca veemos que algunos prinçipes nuestros comarcanos usan esta manera de escrivir deziendo en la supraescripción de la letra «al nuestro devoto». E de aqui pienso que començando esta manera de fablar en Castilla tomamos otras palabras. Ca «voto a Dios» decir tan amenudo en cada afeccion bien sabedes que non se usava en este reyno quando vos erades de veynte años, e témanlo ya por polideza non mirando que es mayor vinculo e atamiento el voto que el juramento. E paresçe que non se contentan de ponerse al peligro del perjurio jurando tan espressamente en livianas cosas si non ayuntan con ello quebrantamiento de voto que es mayor pecado que es perjurio (CORDE).

Otros juramentos hay, aunque las palabras no tengan forma de juramento, tienen la obligación dél, como decir: voto a Dios, prometo a Dios, etc. Las cuales maneras de decir más parescen votos o promesas que juramento. Pero ya el uso de los hombres lo toma por juramento, Y por consiguiente es tanto pecado como decir sin justa causa: juro a Dios, o pardiós, etc. Lo mesmo es destas maneras de decir: por mi vida, o de mi padre, así Dios me ayude, Dios me destruya si no es ansí, y otras semejantes (CORDE).

O de este modo rezan los Estatutos del colegio de Santa María de Burgos de la Universidad de Salamanca (anónimo de 1552):

Item, estatuimos y ordenamos que ningún colegial ni familiar, ni otra persona alguna de este dicho colegio, diga: «Juro» ni «voto a Dios», ni «por vida de Dios», ni «por Dios», ni «por santa María», ni «por nuestra Señora», ni por otra santa ni santo alguno, ni por ángel ni arcángel, diciéndolo ni refiriéndolo, so pena de medio real por cada vez que lo dijere o refiriere, y si más jurare, diciendo alguna otra blasfemia, pague medio ducado por cada vez que lo hiciere (CORDE).

Según señaló Benveniste (1974: 257), otro procedimiento de la blasfemia, también atestiguado en la documentación analizada, consiste en invocar, como él lo llama, a «l'anti-Dieu», al Diablo, en locuciones que habitualmente contienen el nombre de Dios («Válgame Dios»):

diciendo vno balga el diablo, que siempre a la tarde hemos de tener priessa y diciendo otro que mejor era encomendarlo a Dios pues estaua cerca la quaresma, a lo

${ }^{10}$ En 1931 el diccionario de Pagés (s. v. votar), y posteriormente la Academia a partir de su edición de 1936 (cf. NTLLE, s. v. votar) recoge ;voto va! como 'expresión familiar con que se amenaza o se denota enfado, sorpresa, admiración, etc.'. 
qual decían los compañeros quel dicho Reo auía dicho que podía más el diablo que Dios en occassiones (AHN, 1621, lib. 836, $\left.\mathrm{f}^{\circ} 269 v\right)^{11}$.

Los testimonios de la locución valga el diablo se restringen a la literatura del siglo XVII, cuando se constata en autores como Calderón, Moreto, Polo de Medina y Arboreda (cf. CORDE). La documentación examinada en este trabajo ofrece asimismo indicadores pragmáticos y sociolingüísticos de interés sobre el uso de las fórmulas mencionadas, de manera que se pueda caracterizar el léxico empleado en juramentos y blasfemias. Son acusados de estos delitos un cura de la villa de Fresneda - el licenciado Pedro Ezquerra- («voto a Dios»), un carnicero de Artajona de 24 años -Pedro de Legarda- («reniego de Dios y voto a Dios»), un escribano de Payueta, aldea de la villa de Peñacerrada, de 39 años («voto a Dios»), un maestro de escuela de Laguardia de 25 años (《voto a Dios»), un pastelero de Bayona de 23 años (《reniego de Dios»), un labrador de Logroño de 40 años («reniego de Dios y de sus santos»), un administrador de las carnicerías de El Ciego («voto a Dios»), un labrador vecino de Villamediana de 25 años («balga el diablo»), la esposa de un zapatero, vecina de Torrecilla, de 28 años ( «reniego de Dios y de nuestra señora»), un procurador de causas de Murillo de Rioleza de 28 años («reniego de Dios»), un «clérigo presvítero cura y beneficiado en la Iglesia de la villa de Cortil de Carnias de la abadía de Fonçea», de 34 años («voto a Dios»), un labrador de Treviño, de 56 años («reniego de Dios y de la madre que me parió»), un ermitaño de San Bartolomé, en la villa de Urroz, de 40 años («reniego de Dios»), un cordonero de Sangüesa de 40 años («par dios»), la esposa de un zapatero de Nájera, de 27 años («reniego de Dios»), y una mujer de Andosilla de 40 años («reniego de Dios»).

Ya sea en la declaración de los testigos o en la del reo se añaden normalmente indicaciones pragmáticas que llevan a justificar el acto imprecatorio: «estando con enojo», «con mucha cólera y enojo de ver que no le querían llebar vna gabilla de válago para hechar por cama, hauiéndolo mandado el mismo juez, hauía dicho», «estubo tan enojado y sentido que, después de jurar muchos juramentos, tanbién auía dicho», «respondiéndole que sí se auia encendido en colera, de suerte que con el furor de ella queriendo deçir reniego de la leche que mamé auía dicho reniego de Dios», «castigando con cólera y enojo a vna hija suya de diez años, inadbertidamente auía dicho», o bien simplemente añaden información sobre el enunciado propiamente dicho, concediendo más dramatismo al momento: «metió mano a un alfanje que llebaua y dijo: eso sí, voto a Dios, fauor a la justiçia, que son unos desbergonçados y lebantando el alfanje deçía que si alguno se meneaba le abía de abrir de arriba abajo», «auía dicho el reo con mucha cólera tirando vn sombrero o montera que tenía en la caueza». En ocasiones se verbaliza el arrepentimiento posterior, por lo general siempre dramático y con la intención de convencer: «dijo Reniego de Dios, por deçir Reniego del Diablo, y que luego arrojó el tablero y besó la tierra pidiendo perdón» (AHN, 1636, lib. 837, f 7 r r).

Estos textos permiten comprobar que no todas las blasfemias son iguales y no han de juzgarse, por tanto, de la misma manera; de este modo, según dejan ver los testimonios de los encausados, cada una de estas expresiones implicaba un grado de agravio

\footnotetext{
${ }^{11}$ Permítaseme reproducir este diálogo al que haré referencia más adelante ( $\left.c f . \S 5\right)$.
} 
diferente, pues algunos admiten, por ejemplo, la posibilidad de haber proferido «voto a Dios» pero no «reniego de Dios». Así ocurre con el carnicero de Artajona mencionado anteriormente al que se acusa de haber dicho «reniego de Dios, quién a de llebar esta vida» y que «respondió a la acusaçión que solo se acordaua aber dicho algunas veçes estando con enojo por vida de Dios» (AHN, 1633, lib. 836, $\mathrm{f}^{\mathrm{0}} 600 \mathrm{r}$ ). Desde el punto de vista teológico-jurídico, tan ofensivo resulta votar (cf. Tesoro, s. v.) como renegar; la clave para la aceptación del voto y no del reniego ha de ser, probablemente, el distinto grado de desemantización y rutinización, en términos de García-Medall (2008), de ambos verbos, siendo el voto a Dios un lugar común en la lengua de la época ( $c f$. supra), como mostrará su posterior proceso de eufemia en la expresión voto a bríos ${ }^{12}$ (cf. supra). Sucede de igual modo en pardiez como sustituto eufemístico de par Dios o por $\operatorname{Dios}^{13}$, término que ya no se siente como injurioso sino meramente interjectivo, según lo apuntado antes - uso desviado del que se hablaba en las primeras líneas de este trabajo (cf. supra): «que el dicho reo alabando vn macho que tenía hauía dicho: mirad qué potente está mi macho, pardiez, que pareçe a Dios Padre» (AHN, 1624, lib. 836, f $393 r$ ), palabras que blasfeman por la comparación.

\section{INSULTOS E INJURIAS}

H. Haverkate (1994) y J. García-Medall (2008) consideran los insultos ${ }^{14}$ como actos ilocutivos expresivos ${ }^{15}$. En cuanto actos de habla «se caracterizan porque el emisor es indiferente en cuanto al mantenimiento interpersonal de su propia imagen, pero es muy sensible en cuanto a la degradación (mediante material lingüístico) de la imagen ajena» (García-Medall 2008: 667). Añade este mismo autor que estos actos no suelen responder al Principio Cooperativo de Grice; antes bien establecen una relación comunicativa anticooperativa o polémica ( $c f$. García-Medall 2008: 667). Además, como ya se ha señalado antes para el juramento y la blasfemia ( $c f . \S 2)$, el insulto puede cumplir las funciones referencial, conativa o expresiva del lenguaje ( $c f$. Castillo 1998: 24-25 y Herrero 2007: 352-356).

La injuria supone un modo de agresión verbal sobre el destinatario del agravio, que sancionan ya los primeros textos legales hispánicos como las Siete Partidas alfonsíes y las diferentes redacciones privadas de derecho territorial, los fueros, la jurisprudencia - fazañas - los procesos y las Actas de Cortes (cf. Madero 1992, Castillo 1998 y Segura 2005$)^{16}$. Según sugiere D. Lagorgette, insultar o injuriar a otro es, como blas-

${ }^{12}$ Como procedimientos de eufemia sobre la blasfemia señala Benveniste (1974: 257) «le remplacement du nom "Dieu" par quelque terme innocent».

${ }^{13}$ Según otro de los mecanismos indicados por Benveniste (1974: 257), «la mutilation du vocable "Dieu" par aphérèse de la finale [...] ou la substitution d'une même assonance».

${ }^{14}$ Cabrían aquí, según García-Medall (2008: 667), insultos, afrentas, injurias, ultrajes u ofensas como términos sinónimos.

${ }^{15} \mathrm{Cf}$. $\$ 2$ lo señalado a propósito de los juramentos y blasfemias.

${ }^{16}$ Añade Madero 1992, 21: «el lugar que ocupa la injuria en el derecho de Castilla y León de los siglos XIII y XIV y las numerosas leyes que la regulan prueban la importancia de esta noción. Dieciséis de 
femar, una acción en la que decir es hacer; el insulto o la injuria implica, en realidad, una ofensa a Dios:

Le nom commun deviendra alors nom propre; le même phénomène est en général (termes occupationnels, toponymes, etc.). Redéfinir ainsi l'être, si l'on y pense, peut aussi équivaloir à usurper la tache divine: le Créateur se donne à voir dans chacune de ses créatures. Dès lors, renommer l'Autre est comme une micro Genèse, et par le même lien métonymique, insulter l'autre est déjà insulter Dieu (Lagorgette 2003: 176).

Y así lo contempla, como ya se ha visto, la tradición medieval y la lexicografía desde Autoridades ( $c f$. §2). En este sentido puede leerse en la traducción anónima del Libro de las donas de Francesc Eiximenis (1448):

¿Qué dirán a Dios los que a cada palabra que dizen juran a Nuestro Señor Dios? Por cierto son a Dios mucho culpables, por su mal viçio \& desto viene a peor. E sepas que jurar por las criaturas non es menos pecado que jurar por Dios, que quien jura por la criatura jura por aquel que la ha criado (CORDE).

También los documentos analizados son abundantes en testimonios de insultos o injurias, constituidas por términos aislados o sintagmas: un arriero de Torre de Cameros dijo del alcalde «a grandes voçes» que era «un pícaro borrachuelo cornudo» (AHN, 1632, lib. 836, f5579v); un familiar del Santo Oficio vecino de Vituno llamó a una mujer «perra bellaca adúltera» (AHN, 1632, lib. 836, f0581r); el licenciado Miguel García «estando en la plaça publica delante de muchas personas y en voçes muy altas» llamó a Antonio Hurtado de Mendoza «ruyn, suçio puerco» (AHN, 1632, lib. 836, fo581v); una mujer llama a otra «pregonera, buchina ${ }^{17}$ y otras palabras» (AHN, 1637, lib. 837, f $12 r$ ); Pascual Ortiz, familiar del Santo Oficio, se dirigió a Graciosa de Ysal$\mathrm{zu}$ con los calificativos de «pícara quitona» ${ }^{18}$ (AHN, 1639, lib. 837, $\mathrm{f}^{\mathrm{0}} 165 \mathrm{r}$ ); un cura y beneficiado de Noja es acusado de haber proferido los insultos de «picaro, desbergonçado, mal naçido» con el agravante de «auerle dado de puntapiés y vna bofetada a mano abierta» (AHN, 1642, lib. 837, $\mathrm{f}^{0} 216 r$ ); un clérigo presbítero y beneficiado en la Iglesia Parroquial de la Villa de Briñas, de 44 años, se refirió a los frailes y monjas como «zánganos agarradores de las açiendas» (AHN, 1643, lib. 837, fo247r); un vecino de Quejana de 56 años calificó a otro de «grandíssimo bellaco» (AHN, 1621, lib. 836, f 270r); un vecino de Albelda llamó «puerco» a un familiar suyo (AHN, 1625, lib. 836, f $393 v$ ). La visión sociohistórica puede ayudar aquí a entender la diferente significación que la suciedad, representada en ciertos animales, especialmente en el cerdo, tenía en siglos medios y modernos. En efecto, según señala F. Segura, debido a aconte-

los cuarenta y ocho artículos del Fuero de Palencia (1181) y treinta y cinco de los ochenta y cinco que contiene el Fuero de Madrid (1202?) tratan de la injuria y de la honra».

${ }^{17}$ No he encontrado testimonios de esta voz. Podría ser partir de buche, sinónimo entonces del término anterior pregonera. De ser así y de tratarse de una creación aislada, mostraría la creación léxica como procedimiento característico del lenguaje expresivo.

${ }^{18}$ Quitona, que no se registra en CORDE, sería otra creación esporádica del lenguaje expresivo formada sobre el verbo quitar con el significado de 'robar' y en coherencia semántica con el insulto precedente; quitona puede ser además una especificación de pícara o un cuasisinónimo, en virtud de lo cual se suprimiría o se añadiría la pausa, respectivamente. 
cimientos de especial trascendencia social en las centurias medievales como la peste en concreto, la Peste Negra de 1348-,

la invocación de la suciedad y la podredumbre tenía entonces una significación mayor y un amplio espectro de gentes lo asumió como denuesto, [...] Estas recreaciones repulsivas compartían la impureza propia de algunos animales, o al menos sus connotaciones negativas, un simbolismo que recreaba en la bestia los comportamientos humanos indeseables. El juicio peyorativo de la palabra escogía entre sus preferidos del bestiario medieval al perro y al cerdo (Segura 2005: 159-160).

Otro vecino de Aybar de 35 años empleó la expresión «santos de merda» (AHN, 1624, lib. 836, $\mathrm{f}^{\mathrm{0}} 408 \mathrm{r}$ ) para referirse a unas imágenes de santos; un joven llamó «cabrón cornudo» ${ }^{19}$ (AHN, lib. 837, f $\mathrm{f}^{0} 278 \mathrm{r}-305 r$ ) a quienquiera que lo hubiese bautizado; ante una supuesta falsa acusación una mujer de Cárcar de 40 años se dirigió a los testigos, una hija y su padre, como «matamaridos» y «desperjurado», respectivamente, «a que replico él: cuerpo de tal con la mui desbergonçada ${ }^{20}$, que mi hija ni yo no matamos a Christo como buestros antepasados» (AHN, 1626, lib. 836, fo418r). En CORDE se registran tres testimonios de matamaridos: en el primero de 1594 (el Fructus sanctorum, de A. de Villegas) en boca de una criada; en el segundo (drama musical anónimo de 1775) en una seguidilla y en el mismo contexto que este en el tercero (drama musical de 1778 de Blas de Laserna). Desperjurado, que no aparece en $C O R D E$, puede responder a procedimientos propios de la lengua vulgar o coloquial como la interpretación errónea de perjurado 'el que jura en falso' $(D A, s$. v. desperjurar), término en el que no se identifica el valor negativo por lo que se hace necesario añadir el prefijo des-, al modo como sucede, por ejemplo, en cambiar y descambiar.

En una riña entre mujeres una de ellas llamó a otra «puta borracha» (AHN, 1626, lib. 836, $\mathrm{f}^{\circ} 419 v$ ) y un cura que antes ya había votado a Dios y que encontraremos más adelante llamó a sus vecinos «vellacos anbrientos, malditos ynfames» (AHN, 1623, lib. 836, $\mathrm{f}^{0} 335 v$ ). Tanto bellaco como puta son dos de los insultos con más frecuencia de registros en los textos del español desde la Edad Media; el segundo de ellos tiene, por otra parte, una caracterización sociolingüística precisa en la que coinciden diferentes estudios: se trata de un agravio emitido principalmente por mujeres ${ }^{21}$ ( $c f$. Castillo 1998: y Segura 2005: 169) ${ }^{22}$.

Estos insultos en muchas ocasiones son proferidos «a grandes voçes» $\mathrm{o}$ «en la plaça pública delante de muchas personas», hecho que también desde los primeros textos

${ }^{19}$ Señala Herrero (2007: 362) que el término cornudo no se usa como insulto en la Celestina ni en Lisandro y Roselia. No se lee tampoco entre los insultos que F. Segura recoge en documentación navarra bajomedieval (cf. Segura 2005).

${ }^{20}$ Acusa a la rea de judaizante.

${ }^{21}$ Puntualiza Segura al hablar sobre la injuria en documentos medievales que emplean este término más los hombres que las mujeres y que cuenta entre los preferidos por estas últimas ( $c f$. Segura 2005: 169).

${ }^{22}$ Señala Herrero (2007: 361) en su estudio sobre el insulto en la comedia celestinesca: «Respecto a la sexualidad, el insulto más frecuente es el más característico contra las mujeres: puta. No obstante, su uso como agresión verbal directa al interlocutor apenas se da en la Celestina [...] y en la Segunda Celestina [...]; aunque sí alcanza mayor frecuencia en Lisandro y Roselia». 
legales se considera agravante de la injuria; en algún momento a las ofensas con «palabras descompuestas» se añaden circunstancias como «auer dado de puntapiés y vna bofetada a mano auierta».

Coincide este análisis con otros estudios sobre el insulto en épocas pasadas ( $c f$. Castillo 1998 y Herrero 2007) en cuanto a los dominios a los que pertenecen los términos y sintagmas presentes en la documentación estudiada: la sexualidad — puta, perra, adúltera, cabrón, cornudo-, maldad — bellaco y bellaca, desperjurado, infame, mal nacido, matamaridos, pícaro y pícara, ruyn-; defectos de comportamiento desbergonçado y desbergonçada-, que pueden materializarse como robo (agarradores de las açiendas, quitona), bebida (borrachuelo y borracha), maledicencia e indiscreción (buchina, pregonera), pereza (zánganos); voces referidas al aseo —suzio, puerco-; faltan, sin embargo, al contrario de lo que sucede en los estudios mencionados, agravios que atribuyen defectos físicos o mentales.

\section{FÓRMULAS DE DESPRECIO}

A juramentos, blasfemias e injurias ha de añadirse la construcción no dársele a uno seguido de nada o de algún elemento negativo de muy poco valor, al modo de las expresiones actuales con el verbo importar y de las negaciones expresivas documentadas desde los primeros textos literarios. Así, «Francisco de Alday, vezino de la villa de Vilbao, natural del Valle de Oquendo, Alcayde que ha sido de la cárçel de Vizcaya donde estaua presso de hedad de sesenta años», ante la amenaza de otros de dar parte al Santo Oficio por sus afirmaciones, responde «que no se le daua un marauedi» (AHN, 1634, lib. 836, $\mathrm{f}^{0} 654 r$ ); Catalina Gil, muger de un labrador de Briones, de 44 años, «llegándose a tratar de materia del sexto mandamiento había dicho a los dichos sus hijos: andad, no se os de nada» (AHN, 1637, lib. 837, $\mathrm{f}^{\mathrm{0}} 18 \mathrm{r}$ ); un teniente de cura en la Colegial de Logroño, de 30 años, replicó a una persona que le reprendía por andar en los confesonarios: «ique se le da a vm que yo ande en esto?» (AHN, 1635, lib. 836, $\mathrm{f}^{\mathrm{0}} 669 \mathrm{r}$ ). A veces la expresión varía añadiendo complementos introducidos con de o por: un testigo dice haber oído a Garçia de Apeztegui, vecino de Abaurrea Alta, de 46 años, «que no se le daua nada por la Inquisición ni por todo el mundo» (AHN, 1635, lib. 837, $\mathrm{f}^{\mathrm{0}} 3 r$ ); ante unas letras de notificación del Santo Oficio un labrador de Bernedo de 43 años exclama que «no se le daba quatro ongos por ellas» (AHN, 1636, lib. 837, f 25v); un labrador de Cenicero de 45 años contestó a la persona que criticaba su actitud que «no se le dana vn cuerno por el ni por los Inquissidores» (AHN, 1620, lib. 836, f $\mathrm{f}^{0} 208 \mathrm{v}$ ); un carnicero de El Ciego respondió a quien le advertía sobre la gravedad de lo que estaba haciendo que «a él no se le daba nada del tribunal ni de los Inquisidores» (AHN, 1644, lib. 837, fo242r).

Distintas búsquedas en el CORDE arrojan cifras elevadas sobre las ocurrencias de esta fórmula, en especial durante las centurias del quince y del dieciséis, cuya semántica hace que aparezca con frecuencia en situaciones y contextos que podrían calificarse de coloquiales. 


\section{MALDICIONES}

La maldición constituye otra de las maneras de hacer patentes los sentimientos más enconados hacia otra persona y resulta igualmente delictiva que blasfemias, insultos y fórmulas de desprecio en la España de los siglos áureos; como aquellos, las maldiciones se producen - podrá verse en algún contexto- «a grandes voçes» y «con cólera y enojo». El procedimiento es tan antiguo como la lengua y, lo mismo que hoy, existían entonces maldiciones más o menos estereotipadas que, como veremos, a veces han de ligarse por su contenido al modo de vida de cada momento. Según Herrero (2007: 363), «la maldición comporta generalmente un deseo negativo y un acto agresivo que la acerca a algunas propiedades del insulto».

Así, un ginebrino de 23 años renegando del bautismo y afirmando «que quisiera poder quitarse la chrisma que hauia reciuido» acaba maldiciendo de este modo: «mal huuiese el cabron cornudo que se la hauia puesto» (AHN, lib. 837, f $278 r-305 r$ ) donde se une el insulto a la maldición-y en otra ocasión volvió a proferir que «maldita fuese su madre que le hauia hecho venir a baptiçarse y que él también fuese maldito por no haber tomado el consejo de vn primo suyo hereje» (AHN, lib. 837, 1646, fo299v); «Francisco López, clérigo Presvítero cura y beneficiado en la Iglesia de la villa de Cortil de Carnias de la abadía de Fonçea natural della de hedad de treinta y quatro años [...] en ocasión de quexarse de sus veçinos por que no le dauan sus caualgaduras para acarrear el pan de su agosto que tenía en las heredades andaua por las calles de su pueblo dando voçes diçiendo [...] que mala piedra y niebla viniesse sobre quanto auía en el canpo [...] y que diçiéndole vna persona que artas missas les auia dexado vno difunto avía respondido con cólera [...] maldita la que nos dexo, aviéndoles dexado a cada sacerdote ochenta misas» (AHN, 1623, lib. 836, f $331 r$-331v); este mismo cura «con ocasión de que algunos veçinos no le querian prestar sus machos para acarrear el trigo como se husaua, avía dicho con cólera en la calle a bozes [...] maldito sea quanto yo os e conjurado, plega a dios que mala piedra y niebla os venga» (AHN, 1623, lib.

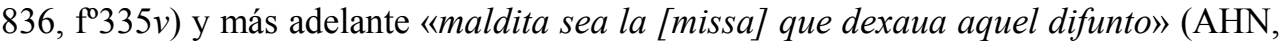
1623, lib. 836, fo336r). Este tipo de expresiones encabezadas, como se ha visto, con el adverbio mal o con el adjetivo maldito, al que se añade el verbo ser, alternan con la mención del diablo en la expresión llevarse el diablo a alguien: el mismo cura al que hemos oído maldecir antes («lleue el diablo las misas»), un escribano de 39 años («que llebase el diablo quien alli lo habia llebado», «que le llebase el Diablo a quien le auia pasado al testigo a aquella tierra»), la esposa de un sastre de Sangüesa de 27 años («el diablo lleue a ella y a la missa»).

Estas fórmulas se combinan con frecuencia en los documentos con el término «cagajón para la Inquisición» o «cagaxón para el Santo Offiçio» ${ }^{23}$, que ha de entenderse

${ }^{23}$ La escasa aparición de esta voz en CORDE ha de justificarse por el carácter esencialmente oral de este tipo de léxico: trece apariciones en diez documentos diferentes, en la misma utilización que en los textos manejados aquí (vg., «iy cagajón para D. Fadrique!», Libro de chistes, de Luis de Pinedo, de 1550). 
incluida en otra expresión más amplia, posiblemente dependiente de un verbo de deseo, cuyos elementos se eliden.

\section{CONSTRUCCIONES DE SIGNIFICADO HIPERBÓLICO}

Por último, el grupo más numeroso, y también el más interesante por su singularidad, es el de las hipérboles, que se formaliza en diferentes estructuras sintácticas, siendo la comparación la más común de todas ellas. Son aquellas a las que E. Stoll se refiere como comparaciones drásticas al analizar la crónica soldadesca de Pedro Pizarro; presenta Stoll estas construcciones como universales por venir condicionadas por situaciones comunicativas determinadas y no deberse a una lengua en concreto. En el plano de la semántica, sigue diciendo la autora, son estos elementos, junto con hipérboles, metáforas y metonimias, los que se presentan en una situación comunicativa en la que prevalezca la emocionalidad, la espontaneidad y la dialoguicidad, «es decir, en lo hablado concepcional o en la inmediatez comunicativa» (cf. Stoll 1996, 435). Se constatan comparaciones simples del tipo «pareçe que viene fulano cargado con su cruz como vn borrico» (AHN, lib. 836, 1620, fo201r); y otras más complejas: un labrador de Bernedo de 43 años «hauía dicho en dicha ocasión que, aunque traxera más excomuniones que rejas había en La Rioja, no le podían dar la posesión de la vara de Alcalde» (AHN, 1636, lib. 837, fo $25 v$ ); varios testigos acusan a un labrador de 52 años, sospechoso de hechicero, de haber pronunciado las siguientes palabras cuando aquellos se pararon a rezar en una ermita de San Jorge: «más quiere san Jorge dos morçillas para çenar que quantas oraçiones y rosarios ay» (AHN, 1637, lib. 837, fo $46 r$ ); varias personas testificaron que un clérigo de 40 años había dicho que «no temía a Dios más que a una lechona»; (AHN, 1623, lib. 836, fo340r-340v); un vecino de Albelda afirmó, siendo acusado por ello de blasfemo, que «no tenía más alma el capellán que su rocín» (AHN, 1624, lib. 836, $\mathrm{f}^{\mathrm{0}} 393 \mathrm{v}$ ). Son numerosas las comparaciones con la estructura antes...que o primero...que: un marinero holandés ${ }^{24}$ de 36 años ante la advertencia de no volver a caer en herejía respondió que «primero moriría mil muertes que caer en heregía alguna» (AHN, 1638,837, f $95 r$ ); por la misma razón un inglés de 22 años se expresó de forma parecida diciendo que «primero moriría antes que faltar al ser católico Romano» (AHN, 1640, lib.837, $\mathrm{f}^{\circ} 155 r$ ); un herrero de 86 años acusado de hechicería se defendió diciendo que lo que él hacía era «con buena y sana yntençión y no con pacto con el Demonio porque antes se colgaría de un árbol» (AHN, 1621, lib. 836, f $220 v$ ); un labrador de 51 años respondió ante el tribunal inquisitorial que las prácticas de brujería que se le imputaban había sido «sin entender ni haber collejido que fuese ofensa de Dios nuestro señor y del santo offiçio porque ha entenderlo se hubiera muerto mill veçes con sus manos antes que hauerlo hecho» (AHN, 1622, lib. 836, fo291v$292 r)$; un cura de 34 años acusado de haber pronunciado unas «palabras de denuesto»

${ }^{24}$ En los casos en los que el reo extranjero desconoce el español se deja constancia en el documento al modo siguiente: «se delato voluntariamente ante el Comisario de la Villa de Viluao en 14 de Abril de 1640 («mediante intérprete por no sauer la lengua española, precediendo el juramento necessario») (AHN, 1640, lib. 837, fo $155 v$ ). 
exclama «con lágrimas y mucho arrepentimiento que quisiera auerse muerto primero que averlo dicho» (AHN, 1623, lib.836, f $335 v$ ); un herrero y puñalero de 25 años «lastimado y alterado y çiego de impaçiençia volbiendo los ojos al çielo hauía dicho, pues sý, aquello hacia Dios que no creýa en él, cossa que quisiera antes hauerse muerto que atrebidose a deçirla» (AHN, 1625, lib. 836, 398v); un verdugo de 25 años reconoció su delito de herejía «pidiendo misericordia y diciendo quien se estaua ensignando lo hizo y que antes quisiera ser quemado viuo que hauer cometido tal pecado» (AHN, 1625,lib. 836, fo $405 r$ ).

La exageración está presente del mismo modo en construcciones condicionales: «y lebantando el alfanje deçia que si alguno se meneaba le abia de abrir de arriba abajo» (un cura de Fresneda) (AHN, 1632, lib. 836, f 580v); «y ambos diçen le reprehendieron diçiendo era de fee catholica que le había [infierno] y que si no le ubiera nos sacáramos los ojos unos a otros» («testigos mayores, marido y mujer») (AHN, 1632, lib. 836, f0592r); «si yo fuera buen saludador, de un soplo hechara a rodar toda esta gente ayá abajo» (sastre de 19 años) (AHN, 1644, lib. 827, f 267v-268r); «púsosele la acusaçión en 5 de junio del dicho año y a los capítulos della fue negando la solicitazión diçiendo que cayese vn rayo del çielo sobre él si tal hubiese pasado» (cura de 48 años) (AHN, 1625, lib. 836, 402r); también en concesivas: «y que después, abiendo querido haçer vida con ella de allí a quatro años, por que ella le respondió que aunque la matasen no lo haría, la dejó» (hija de un sastre, 18 años) (AHN, 1633, lib. 836, fo607r); «y avnque me diesen cien mil tormentos y me hiciesen pedaços y me hechasen al ynfierno para sienpre, yo no sabría ni podría decir otra cosa» (AHN, 1622, lib. 836, fo295r); «boto a christo que aunque supiera bender el sanctisimo sacramento para salir de vna galera, no dixera yo lo que me pedís» (cura de 34 años) (AHN, 1623, lib. 836, f $331 r-331 v$ ); o cualquier otro tipo de construcciones: «y que en otras ocasiones se andaba quejando dél y de otros dos testigos diçiendo que le hauia de comer los hígados al dicho testigo nuebe» (cura de 44 años) (AHN, 1635, lib. 836, fo657r).

\section{CONSIDERACIONES FINALES}

De acuerdo con otros estudios (cf. Usunáriz 2005: 199-204) y según lo constatado en estas páginas, puede afirmarse que palabras y expresiones malsonantes no son propiedad de una clase determinada, de formación escasa o nula, antes bien son muchos los trabajos que han defendido, por ejemplo, la universalidad del delito de blasfemia ${ }^{25}$. No obstante, sí se ha llegado a establecer un perfil más o menos determinado, hombres jóvenes de sectores al margen de la sociedad religiosa y política del momento («marineros, soldados, arrieros, que escapan de alguna manera al control social, o que, por el hecho de pertenecer al oficio asumen el juramento como un vocabulario propio y distintivo del grupo», Usunáriz 2005: 201). Esto no significa, sin embargo, que la blasfe-

\footnotetext{
25 «nobles, campesinos, artesanos, estudiantes... están presentes en los tribunales civiles y eclesiásticos de toda Europa» (Usunáriz 2005: 200).
} 
mia y otros delitos verbales sean exclusivos de los jóvenes y de oficios de difícil control $^{26}$.

Como se ha visto en $\S \S 2-6$, los oficios de los imprecadores son de lo más variado y no sólo injurian, blasfeman y maldicen los hombres, también lo hacen las mujeres. La realidad presente en los documentos del corpus estudiado constata, por tanto, que las blasfemias y otras imprecaciones eran patrimonio del pueblo que, al igual que hoy, daba rienda suelta a su verbalidad más torpe $e^{27}$ en cuanto la situación lo propiciaba y es aquí donde el lingüista encuentra testimonios vivos de la materialización de las funciones del lenguaje en el siglo XVII. Esta afirmación puede hacerse extensiva a las que se han denominado construcciones de significado hiperbólico, que ya constituyan delito o no, no muestran preferencias de sexo, edad o condición.

Resultan fácilmente predecibles, y la documentación así lo comprueba, las distintas situaciones en las que se producen estos delitos verbales ${ }^{28}$. No es poca la literatura existente sobre el juego en estos Siglos de Oro, celebrado en las tabernas y acompañado, por tanto, de las protocolarias medidas de vino o aguardiente; el juego y el alcohol, entonces como hoy, hacen al individuo capaz de proferir las palabras y expresiones más «suçias y torpes» ${ }^{29}$. Es entonces cuando se leen en esta documentación injurias, imprecaciones, términos malsonantes y todo tipo de expresiones hiperbólicas. En los textos analizados son innumerables las ocasiones en que se hace referencia al juego de naipes y se esgrime la embriaguez como elemento exculpatorio: «no se acordaua ni sauía que fue porque auía bebido más de lo justo» (AHN, lib. 836, fo275r). Con gran frecuencia se lee en estas circunstancias la expresión «no sabía lo que me hacía».

Se produce entonces una explosión incontrolada que se manifiesta en lo que se puede denominar lenguaje afectivo y que cada uno verbaliza según su costumbre. Es decir, cuando desaparece el control afloran, en la mayoría de las ocasiones, los hábitos más enraizados. Los datos lingüísticos vienen a corroborar los históricos cuando estos plantean (cf. Usunáriz 2005: 204-208) que se blasfema por costumbre y se blasfema con especial profusión en estos siglos por la omnipresencia de lo religioso en la vida cotidiana, lo que implica una relación cada vez más familiar con lo sagrado que permite afirmar «se blasfema, simplemente, porque se cree» (Usunáriz 2005: 208), sin necesi-

${ }^{26}$ Según los datos que maneja Usunáriz procedentes de la misma documentación estudiada aquí, casi un $60 \%$ de los blasfemos se reparte entre campesinos y artesanos. Sí se demuestra que el $88 \%$ son varones pero solo el $48 \%$ de los acusados se mueve en edades comprendidas entre los 16 y los 35 años ( $c f$. Usunáriz 2005: 201 y n. 26).

En los testimonios presentados puede verse la cantidad de «imprecadores» que sobrepasa los 35 años.

${ }^{27}$ «Palabras torpes» es otra denominación que aparece en los documentos estudiados para referirse al léxico prohibido

${ }^{28}$ Señala Usunáriz (2005: 202) en el estudio mencionado que por este motivo la legislación empezó en el siglo XVII una campaña para prohibir los juegos de azar.

${ }^{29}$ Como ya se ha dicho en una de las notas precedentes ( $c f$. n.29), de este modo o similar («palabras feas y torpes») evita el escribano en algunas ocasiones en la documentación inquisitorial la reproducción de términos malsonantes o agraviantes. 
dad de buscar justificaciones más trascendentes si se quiere pero menos verosímiles como la subversión política, la inversión social o el ateísmo de los tiempos moder$\operatorname{nos}^{30}$.

Se blasfema, se insulta o se maldice por costumbre y habrá que decir por costumbre o hábito lingüístico cuando, como hemos visto, se reúnen las condiciones adecuadas. Como en todo aquello que se realiza por hábito, lo mecánico puede sustituir a la reflexión, lo que traducido en términos lingüísticos equivaldría a decir que puede producirse la desemantización de palabras o expresiones empleadas ${ }^{31}$.

Se comprueba, en efecto, en los datos recogidos tanto la desemantización de algunos términos, tras la lexicalización, cuanto la utilización plena del significado e incluso la creación de nuevos términos más expresivos que los ya existentes. Y esto se demuestra en tres de los cinco grupos analizados — blasfemias, injurias y maldiciones-. Al igual que sucede hoy, en la mayoría de las ocasiones el hablante no es consciente del significado de la imprecación; más aún, quizá haya que admitir que ni siquiera le interesa; es la rutinización a la que se refiere García-Medall al hablar del insulto en la cultura española frente a otras como, por ejemplo, la británica ${ }^{32}$. No busca la palabra o expresión como portadora de un significado determinado sino como elemento indicador de un estado de ánimo; en la medida en que el grado de emoción aumenta, aumenta también cualitativa y cuantitativamente el léxico empleado y, según la costumbre lingüística, la elección será una u otra con independencia posiblemente del significado.

Evidentemente, esto sucede en los agravios más hirientes; por el contrario, en otros casos el empleo de un término con su significado es tan consciente que, a falta de otro más preciso o conocido, se crean, como señalaba antes, algunos más expresivos: «zánganos, agarradores de las açiendas», «matamaridos», «buchina».

Habrá que distinguir, por tanto, entre actos enunciativos cuya finalidad es únicamente agredir de cualquier modo al interlocutor y aquellos que intencionadamente usan la palabra para acusar o calumniar con su significado. En el primer caso podrían incluirse entre los registrados aquí bellaco, desbergonçado, ruin, sucio, puerco, puta ${ }^{33} \mathrm{y}$ en los segundos, pregonera, zánganos, matamaridos, etc.

También las fórmulas de juramento sirven para ejemplificar esta doble vertiente. Mientras en unas ocasiones el hablante que las emite no es consciente de lo que está diciendo, como parece advertir ya Covarrubias (Tesoro, s. v. votar) en su comentario a la expresión voto a Dios; en otras se actúa rompiendo una fórmula fija.

Recuérdese el mencionado «balga el diablo» al que el interlocutor responde «que mejor era encomendarlo a Dios, pues estaua cerca la quaresma» (cf. §2). En las maldiciones la fórmula invariable es la que emplea el adjetivo maldito (maldita fuese su

\footnotetext{
${ }^{30} C f$. para todas estas teorizaciones las páginas citadas (204-208) de Usunáriz 2005.

${ }^{31} C f$. lo dicho páginas más atrás sobre la desemantización y rutinización de los insultos (cf. §4).

${ }^{32}$ Cf. García-Medall (2008: 668).

${ }^{33}$ Algunos términos como este podrían entrar en los dos grupos. Insisto en que la clave no es el vocablo o la expresión en sí sino el uso que de ellos se lleva a cabo.
} 
madre, maldito sea quanto yo os e conjurado, etc.) o el sustantivo mal seguido normalmente del verbo haber (mal huuiese el cabrón cornudo que se la hauía puesto). La creación novedosa aparece cuando la maldición viene encabezada por el adjetivo mal(o)/mala al que se añade el sustantivo malintencionado: «mala piedra o niebla os venga» (cf. §5). No pueden aplicarse las mismas palabras, sin embargo, a las fórmulas de desprecio ni a las expresiones hiperbólicas que se basan precisamente en el aspecto semántico para la creación de un lenguaje expresivo, dramático o cómico, según el momento (cf. $\S \S 5-6)$.

Un factor común a todos los casos presentados es la indicación pragmática que ha ido señalándose convenientemente en cada apartado y que no repetiré. Estos elementos cobran en el caso del lenguaje expresivo una trascendencia especial al comprobar que el dramatismo de una escena no se consigue únicamente con las palabras sino con elementos tales como entonación y gestos, que el relator intenta salvar en la escritura de la mejor manera posible ( $c f . \S \S 2-6)$, como sucede en este caso: «hauía respondido que no importaba nada vn poco de agua que le hauían hechado por la caueça (diciéndolo por el baptismo) y que, haciendo ademanes de desprecio, había dado vn soplo, dando a entender que era cosa de aire» (AHN, 1646, lib.837, fo299v).

Esta circunstancia, el interés del escribano por dejar constancia de todos los detalles del acto enunciativo, se muestra abiertamente en el momento de la declaración del reo, que es descrita con profusión de detalles en el sentido apuntado. Sirva este ejemplo como prueba:

declarando que anbas cossas las hauia hecho con ygnorancia y sencillez sin entender ni haber collegido que fuese ofensa de Dios mismo nuestro señor ny del santo oficio porque ha entenderlo se hubiera muerto mill veçes con sus manos antes que haberlo hecho. Y así pidió misericordia con grandes solloços, lágrimas y suspiros, lamentándose muy tiernamente de su trabajo y afiçión, con que se betó la caussa en conformidad a veinte y siete de março de seiscientos y viente y tras que sin haçérsele processo al rreo fuese adbertido y reprehendido y despachado con esto, sin más delazión, executose (AHN, 1622, lib. 836, f²291v-292r).

Es cierto también que, según los distintos escribanos, resulta diferente el grado de exhaustividad e implicación - repárese en tiernamente en el ejemplo anterior-. Sería este aspecto cuestión de otro análisis, al igual que otros que han aparecido dispersos por estas líneas, lo que creo que comprueba el trabajo que todavía queda por hacer sobre documentaciones como la que aquí se ha manejado.

\section{REFERENCIAS BIBLIOGRÁFICAS}

BACH, Kent y Robert M. HARNISH (1979): Linguistic communication and Speech Acts, Cambridge, Cambridge Mass, MIT Press. 
Benveniste, Émile (1974): «La blasphémie et l'euphémie», en Problèmes de Linguistique Générale, Paris, Gallimard, 2, pp. 254-258.

BURKE, Peter (1996): Hablar y callar. Funciones sociales del lenguaje a través de la historia, Barcelona, Gedisa.

Bustos Tovar, José Jesús (2004): «Hablar y escribir en los albores del Siglo de Oro», Edad de Oro, 23, pp. 53-70.

CASTILlo, Mónica (2004): «De verbo vedado: consideraciones lingüísticas sobre la agresión verbal y su expresión en castellano medieval», Cahiers de linguistique et de civilisation hispaniques médiévales, 27, pp. 23-35.

COVARRUBIAS, Sebastián de (2006 [1611]): Tesoro de la lengua castellana o española, ed. integral e ilustrada de I. Arellano y R. Zafra, Madrid, Iberoamericana [Tesoro].

CoLín, Marisela (2003): El insulto: estudio pragmático-textual y representación lexicográfica, tesis de doctorado, en http://www.tdr.cesca.es/TESIS_UPF/AVAILABLE/TDX1230103-114332//tmcr1de1.pdf.

EBERENZ, Rolf (1994): «Los tratamientos en las actas de la Inquisición de Ciudad Real (1484-1527)», Iberoamericana, 18, pp. 73-87.

(1998): «La reproducción del discurso oral en las actas de la Inquisición (siglos XV y XVI) », en W. Oesterreicher, E. Stoll y A. Wesch, ed., Competencia escrita, tradiciones discursivas y variedades lingüisticas. Aspectos del español europeo y americano en los siglos XVI y XVII, Tübingen, Gunter Narr Verlag, pp. 243-266.

(2003): «En busca de la palabra viva. Sobre la representación de la lengua hablada en las actas de la Inquisición», en I. Carrasco Cantos, coord., El mundo como escritura. Estudios sobre Cervantes y su época, Analecta Malacitana, Anejo 48, Málaga, Universidad de Málaga, pp. 59-77.

- y Mariela DE LA TORRE (2003): Conversaciones estrechamente vigiladas: interacción coloquial y español oral en las actas inquisitoriales de los siglos XV a XVII, Zaragoza, Pórtico.

GARCÍA-MedALL, Joaquín (2008): «El insulto desde la pragmática intercultural», en A. Álvarez Tejedor, coord., Lengua viva. Estudios ofrecidos a César Hernández Alonso, Valladolid, Universidad de Valladolid-Diputación de Valladolid, pp. 667-680.

HAVERKATE, Henk (1994): La cortesía verbal. Estudio pragmalingüístico, Madrid, Gredos. 
Herrero RuIZ DE LoIZAGA, Francisco Javier (2007): «El insulto en la comedia celestinesca», en L. Cortés et alii, coords., Discurso y oralidad. Homenaje al prof. J. J. de Bustos Tovar, Madrid, Arco/Libros, I, pp. 349-365.

Lagorgette, Dominique (2003): «Les syntagmes nominaux d'insulte et de blasphème: analyse diachronique du discours marginalisé», Thélème.Revista Complutense de Estudios Franceses, número extraordinario, pp. 171-188.

LOETZ, Francisca (1998): «La petite déliquence du blasphème: jurons et jurements dans l'état de Zurich (vers 1450-1798)», en B. Garnot, ed., La petite délinquence. Du Môyen Âge à l'époque contemporaine, Dijon, EUD, pp. 418-430.

Madero, Marta (1992): Manos violentas, palabras vedadas. La injuria en Castilla y León (siglos XIII-XIV), Madrid, Taurus.

Montero, Emilio (2007): «Palabras malas \& villanas (Alfonso X: Partidas). La oralidad en las tradiciones discursivas jurídicas», en en L. Cortés et alii, coords., Discurso y oralidad. Homenaje al prof. J. J. de Bustos Tovar, Madrid, Arco/Libros, I, pp. 391-399.

REAl ACADEMIa EsPañola (1726-1739): Diccionario de Autoridades, edición facsímil, 3 vols., Madrid, Gredos, 1990 [DA].

(2001): Nuevo Tesoro Lexicográfico de la Lengua española, Madrid, Espasa, ed. en DVD [NTLLE].

-: Banco de datos [en línea]. Corpus diacrónico del español. http://www.rae.es [CORDE].

RIDRUEJO, Emilio (2005): «El juramento. Sobre la especificidad cultural y social de los actos de habla» en L. Santos Río, J. Borrego Nieto, J. F. García Santos, J. J. Gómez Asencio y E. Prieto de los Ríos, eds., Palabra, norma, discurso. En memoria de Fernando Lázaro Carreter, Salamanca, Universidad de Salamanca, pp. 997-1008.

SEgurA, Félix (2005): «Verba vituperosa: el papel de la injuria en la sociedad bajomedieval», en R. García Bourrelier y J. M. Usunáriz, eds., Aportaciones a la historia social del lenguaje: España, siglos XIV-XVIII, Madrid-Frankfurt, Iberoamericana-Vervuert, pp. 149-195.

STOLl, Eva (1996): «Competencia escrita de impronta oral en la crónica soldadesca de Pedro Pizarro», en T. Kotschi, W. Oesterreicher y K. Zimmermann, eds., El español hablado y la cultura oral en España e Hispanoamérica, Frankfurt-Madrid, VervuertIberoamericana, pp. 427-446. 
USUNÁRIZ, Jesús María (2005): «Verbum maledictionis. La blasfemia y el blasfemo de los siglos XVI y XVII», en R. García Bourrelier y J. M. Usunáriz, eds., Aportaciones a la historia social del lenguaje: España, siglos XIV-XVIII, Madrid-Frankfurt, Iberoamericana-Vervuert, pp. 197-221.

WARNOCK, Geoffrey James (1973): «Some Types of Performative Utterance», en I. Berlin et al., eds., Essays on J. L. Austin, Oxford, Clarendon Press, pp. 69-89. 